\title{
Using participatory GIS to examine social perception towards proposed wind energy landscapes
}

\author{
Andrea Lombard \\ Department of Geography, University of South Africa
}

\begin{abstract}
Thirteen onshore wind farm projects, totalling approximately 700 wind turbines, are proposed for the West Coast Region (WCR) of the Western Cape Province in South Africa. Wind energy exploitation possesses the ability to transform what can be classified as natural landscapes into landscapes of power, making the type of landscape on which wind turbines are deployed a prominent factor in its social acceptance or rejection. This paper examines the landscape aesthetics and land use interference of proposed wind farms in the WCR of South Africa through determining if social acceptance or rejection of proposed wind farms is dependent on the residents and visitors scenic and land use valuation of the natural landscape. The results indicate that the visual intrusion of wind turbines is the impact that respondents are least concerned with contrasting with the findings of international literature and further reasons for this anomaly are interrogated against the background of South Africa's dire electricity needs. The paper concludes that visual impact assessments alone are not sufficient for evaluating landscapes and this paper recommends that participatory geographic information systems (PGIS) be used in addition to existing wind energy landscape assessments.
\end{abstract}

Keywords: wind energy landscapes, participatory GIS, South Africa

\section{Introduction}

The development of onshore wind energy is environmentally and socially controversial, with concerns stemming largely from the transformation of natural landscapes into landscapes of power (Pasqualetti, 2000). Landscape character is significant, i.e. what the landscape looks like and which qualities it possesses. This determines whether wind farm projects conform to the overall character of the landscape (Henningsson et al., 2013).

The West Coast Region (WCR) of South Africa is being targeted by wind energy developers because of the region's proven sustainable wind resources (Diab, 1995; Lombard, 2010). The region is renowned for its unique fisherman's culture, untouched natural landscapes that promote tranquillity and its small towns with their unpretentious atmosphere that offers a special quality of life for residents. Recent proposals for establishing a number of wind farm projects in the region are potentially threatening to the character of the WCR landscape. The aim of the research was to establish whether the social acceptance or rejection of proposed wind farms in the region is dependent on the residents and visitors scenic and land use valuation of the natural landscape. The overall objective is to critique wind farm visual and landscape impact assessment practice to determine if alternatives such as participatory geographic information systems (PGIS) would make a valuable contribution to this type of assessment. The paper first reviews existing scholarship on wind energy landscapes and assessment practices. Second, the research methods are reported and the study area - the WCR - is introduced. Third, the results are presented and discussed in detail. Last, the main findings are summarized and the paper concluded.

\section{Background: Wind energy landscapes}

The installation of wind turbines on natural landscapes is generally perceived to have a negative impact on the value of the landscape (Pasqualetti, 
2000; Lothian, 2008). However, the valuation of the landscape differs between types of landscape, individuals as well as different wind energy projects. In some instances, the development of wind farm projects may even complement the character of the landscape. This paper investigates the impact of wind farms on landscapes in two manners, first the visual impact of wind turbines on landscapes and second the diversification of land use coupled with wind farm development.

\subsection{Visual intrusion of wind turbines}

The visual impacts of wind farms is undoubtedly the most controversial issue in wind farm development because wind turbines are accused of ruining the scenic value of landscapes (Pasqualetti, 2000; 2001). EWEA (2010) indicates:

Wind turbines are man-made vertical structures with rotating blades, and thus have the potential of attracting people's attention. Typically wind farms with several wind turbines spread on the territory may become dominant points on the landscape.

The accusation does not hold everywhere as wind farms are not necessarily built where landscapes have scenic value. Some features in the design and siting of wind farms have been identified to minimize their potential visual impact (Hecklau, 2005; Stanton, 2005; Brusa and Lanfranconi 2006). Van de Wardt and Staats (1988) have made it clear that the type of landscape in which wind turbines are deployed is the most significant factor in visual landscape evaluations fully overshadowing all other visual and scenic factors of wind farms.

As stated by Wolsink (2012), the conception of 'visual impact' almost spontaneously classifies the impact on the landscape as negative. The visual impact is especially high in areas which lack any other form of human interference, for example natural, undisturbed landscapes free of any form of development (Katsaprakakis, 2012). Whether these turbine structures have positive or negative impacts on the aesthetic value of a landscape is a matter of individual opinion and the nature of the impacts is determined specifically by the type of surroundings (Wolsink, 2007). One of the main concerns in terms of bucolic landscapes is the influence of wind farm development on tourism in the area. While a tourist might see a landscape as a natural space with an aesthetic value and view it as a 'picture postcard', a farmer might see it as a 'production landscape' where the development of wind farms can lead to land use and income diversification.

\subsection{Land use diversification}

Land not only provides a material basis for the economy, it also gives us cultural meanings such as a 'sense of place and a sense of history' (Lobley and
Winter, 2009: 7). Land and its use represent the core relationship between the natural environment and human activity. Wind farm development will change the use of land or diversify it to a certain extent. Manwell et al. (2002: 502) describes the relationship between land use and wind energy as one that is 'sometimes considered to be land intrusive rather than land intensive'.

This study mainly focuses on agricultural areas as wind farms are often developed on land used exclusively for agricultural purposes. It is advisable to develop wind farms on low-potential agricultural land, thereby supplementing farm income without adversely affecting agricultural production. The development of wind farms in agricultural landscapes can result in a multifunctional countryside, but if the potential wind farm areas surrounding farmland also have tourism value, conflict might arise. It is therefore cardinal that landscape assessment practice should be conducted properly.

\subsection{Investigating landscape assessment practice}

According to Wolsink (2012) the landscape assessment associated with wind power varies because of three factors which are:

1. the landscape impact varies widely among cases, as the character of the landscape is very different at different locations;

2. within each landscape there are many distinguishable elements that may be differently affected;

3. the valuation of the impact shows a wide variety among individuals: some can positively value landscape elements, whereas other individuals value the same element negatively.

Ideal landscape assessment practice should focus on landscape character, landscape value, landscape capacity and landscape sensitivity as a whole and not as homogenous entities. Unfortunately, landscape assessment practice focuses too often on the objectification of the landscape making use of only visual impact assessments. Current techniques of landscape assessment also rely almost solely on specialist perspectives without incorporating the indigenous knowledge of the local people at grassroots level. This study suggests a method first explored by Brown and Raymond (2007) as a way of integrating the local people into the spatial planning of wind energy landscape assessments.

\section{Methods and study area}

The case study area is part of the WCR in the Western Cape Province of South Africa. The whole WCR consists of six sub-regions of which this study involved parts of the Swartland and Bergrivier subregions and the whole West Coast Peninsula subregion portrayed in Figure 1. References to the WCR in this paper all imply the extent of the study 


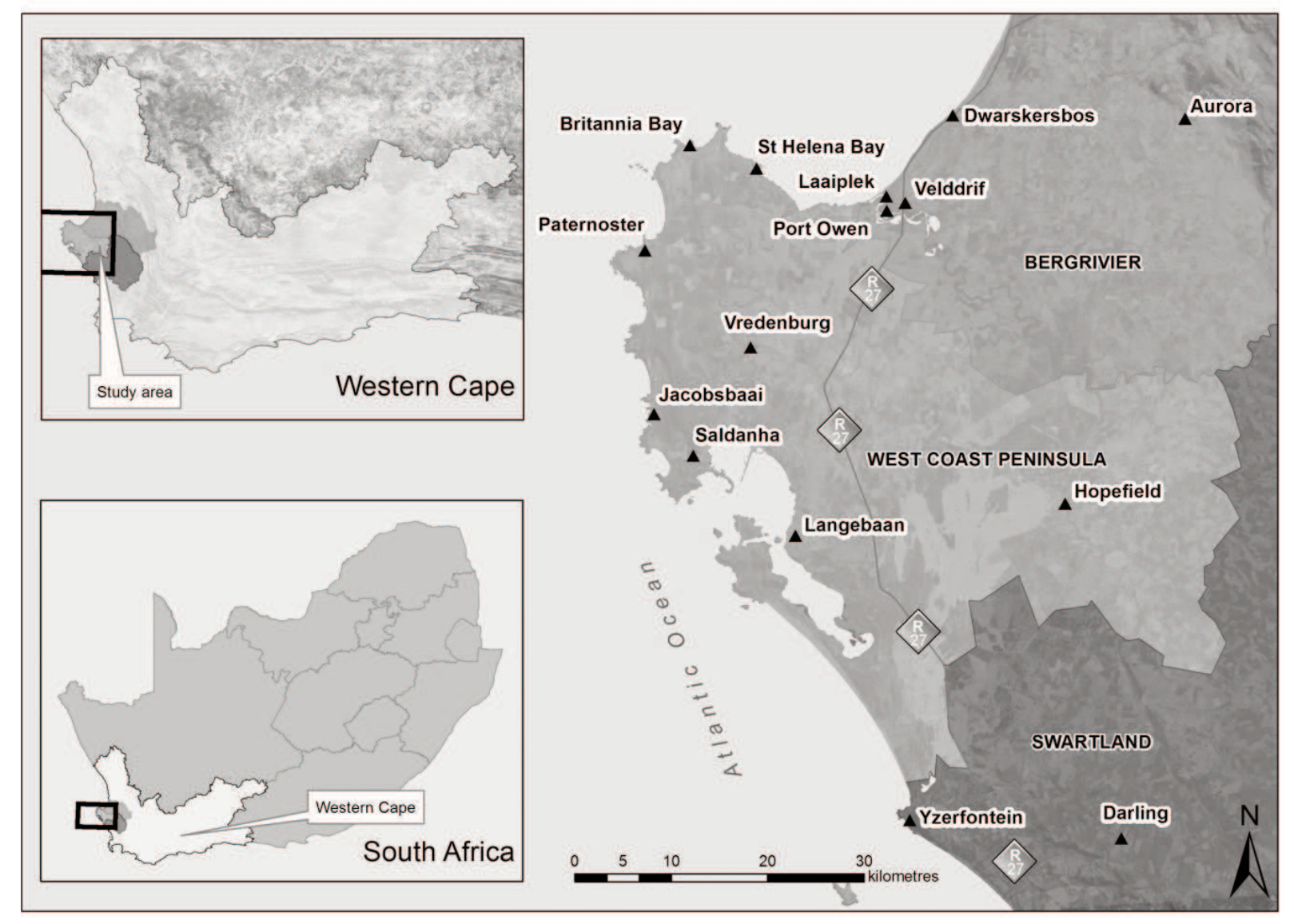

Figure 1: The study area within the West Coast region, Western Cape, South Africa Source: Lombard, 2013

area described here and depicted in Figure 1, unless specified otherwise.

The three sub-regions spotlighted in the study boasts special contrasting landscape features ranging from beautiful and often deserted coastlines along the West Coast Peninsula and Bergrivier subregions to vineyards and wheat farms in the Swartland sub-region all of which appeal to the local residents and visiting tourists. The key economic sectors of the WCR are agriculture, fisheries, manufacturing, mining and tourism (West Coast District Municipality, 2012). This study area was selected because it is the focus of 13 proposals for wind farm projects which will incorporate approximately 700 wind turbines.

This empirical study made use of a questionnaire to elicit information from both residents of and visitors to the WCR. The questionnaire was also the main research instrument used in a broad- er study on the perceptions and attitudes of the residents of and visitors to the WCR concerning: (1) their place attachment and knowledge of the region; (2) the effects of wind turbines on the natural landscape and; (3) the anticipated influence of the proposed wind farm projects on the tourism industry (Lombard, 2013). This paper reports on the second component of the questionnaire concerning the perception of the proposed wind farm projects on the WCR natural landscape. A total of 410 questionnaires were distributed to both residents of and visitors to the WCR either in person, via post or by using a web-based questionnaire (Surveymonkey). Table 1 shows the number of questionnaires distributed among the two target groups as well as the various response rates.

The response rate of $36 \%$ for the 410 distributed questionnaires and the absence of a purposeful stratification of the sample limit generalizations from

Table 1: Questionnaire distribution and response rates

\begin{tabular}{lcccccc}
\hline $\begin{array}{l}\text { Respondent } \\
\text { category }\end{array}$ & $\begin{array}{c}\text { Number via } \\
\text { hand } \\
\text { distribution }\end{array}$ & $\begin{array}{c}\text { Response rate } \\
\text { for hand } \\
\text { distribution }\end{array}$ & $\begin{array}{c}\text { Number via } \\
\text { Internet } \\
\text { distribution }\end{array}$ & $\begin{array}{c}\text { Response rate } \\
\text { for Internet } \\
\text { distribution }\end{array}$ & $\begin{array}{c}\text { Total } \\
\text { distributed }\end{array}$ & $\begin{array}{c}\text { Total } \\
\text { response } \\
\text { rate }\end{array}$ \\
\hline Residents (insiders) & 150 & $55(37 \%)$ & 100 & $43(43 \%)$ & 250 & $98(39 \%)$ \\
\hline Visitors (outsiders) & 50 & $15(30 \%)$ & 110 & $35(32 \%)$ & 160 & $50(31 \%)$ \\
\hline Totals & 200 & $70(35 \%)$ & 210 & $78(37 \%)$ & 410 & $148(36 \%)$ \\
\hline
\end{tabular}


this study. The conclusions drawn are applicable to the respondents and should not be interpreted as representing the views of the entire population of the WCR.

This study focused on the pre-construction phase of these projects and the low response rate can therefore be attributed to unfamiliarity with the proposed projects. A significant number of tourists also indicated that for them the WCR will always be a place to visit and therefore they are not interested in completing the questionnaire as they only frequent the region on a temporary basis.

Figure 2 shows that ninety-one per cent of the responding residents were 41 or older, including nearly half $(47 \%) 61$ or older. Most (more than three out of four) resident respondents live in the

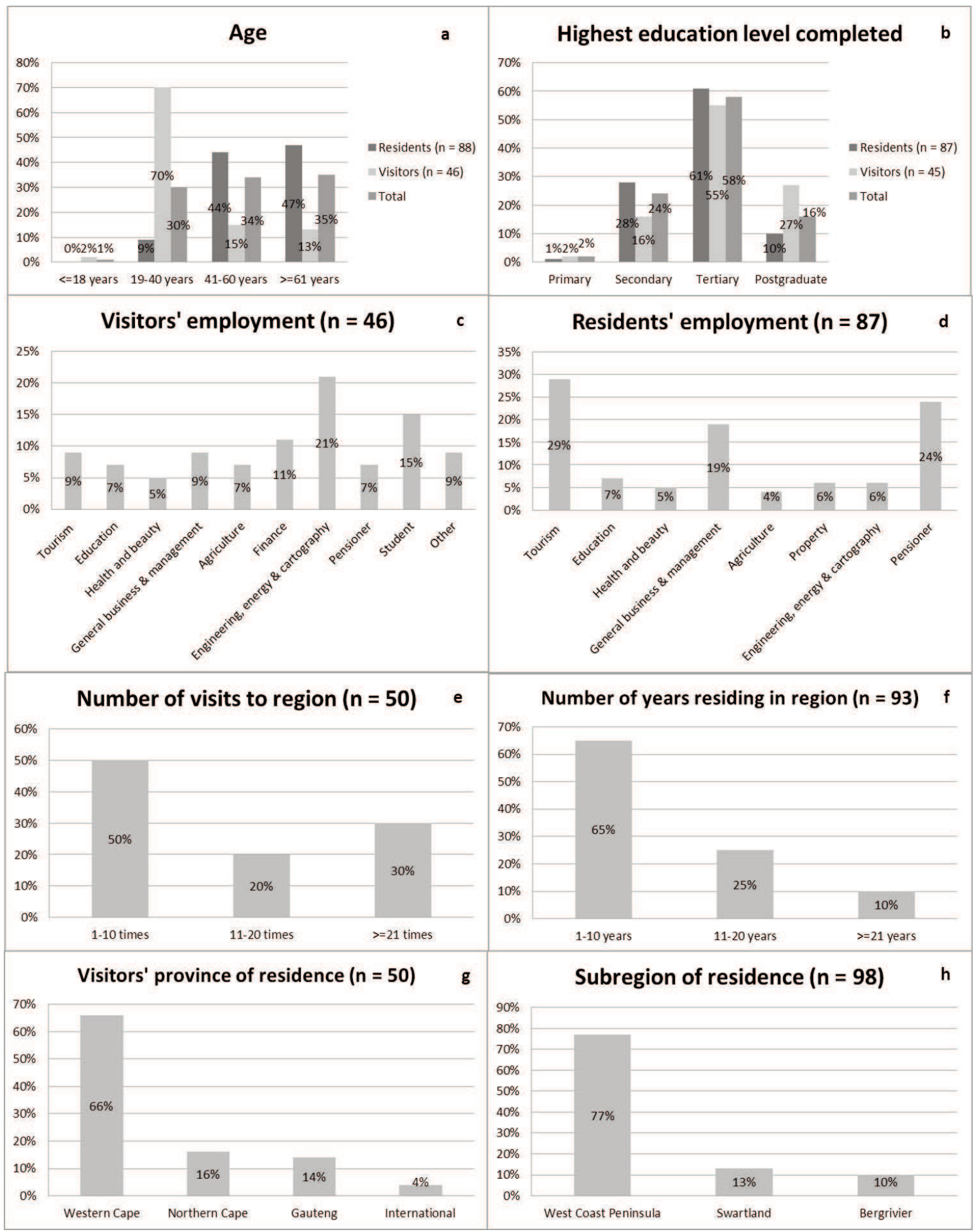

Figure 2: The demographical details of respondents to the survey Source: Questionnaire survey 2012 
West Coast Peninsula sub-region, where the coastal towns are popular retirement places. The major difference between the resident and visitors groups is their age distribution in that $70 \%$ of the visitors were in the 19-40 years cohort opposed to only $9 \%$ of the resident respondents. From the perspective of tourism planning for the region, the views of younger generations are important.

Most resident respondents (29\%) are employed in the tourism industry, while engineering, energy and cartography represents the largest proportion (21\%) of the visitors' employment. Twenty-four per cent of the residents are pensioners, while $15 \%$ of the visitors are students corresponding with the age distribution trend. The education levels attained by both groups of respondents are high, with more than $70 \%$ each having a tertiary or higher qualification. Sixty-five per cent of residents have lived between one and ten years in this region, whilst only $10 \%$ have lived in the WCR for more than 21 years. Half of the visitor respondent group indicated they have visited the WCR between one and ten times, whereas $30 \%$ have visited the region 21 times and more. The fact that eight of the 13 proposed windfarms are earmarked for the West Coast Peninsula probably accounts for the overwhelming $(77 \%)$ representation of respondents from this subregion. Very few international tourists participated in the survey as the WCR is mainly a domestic tourist destination. Most of the visitor respondents hailed from the Western Cape (77\%), with Cape Town contributing $38 \%$. With the WCR being only $85 \mathrm{~km}$ from Cape Town - and part of the pleasure periphery of Cape Town - it is not unexpected that most of the visitors reside there.

The questionnaire survey commenced with the researcher's attendance of public participation meetings where attendees were identified as prospective respondents. All members of the public were invited to these meetings by project develop- ers, so that people from different population groups and socio-economic levels attended. The researcher went from door to door in different neighbourhoods in the 15 towns and villages to invite people who were available and willing to complete the questionnaire. An announcement about the survey was also published in the local newspaper, the Weslander, to which all sections of the community have access in an attempt to make the survey more representative. The surveying of insiders and outsiders of the region has contributed to the inclusiveness of the research. The first round of data collection relied on convenience sampling. When convenience sampling failed to secure an adequate number of respondents, a process of snowball sampling was employed. Snowball sampling involves "using one contact to help you recruit another contact, which in turn, can put you in touch with someone else' (Valentine 1997: 116). Insider knowledge of residents to help identify potential respondents family members, friends, colleagues and anyone willing to participate in the survey - was reverted. This proofed to be an effective sampling technique.

A section of the questionnaire focused on a map-based method of collecting data on landscape values associated with the WCR. This method of data collection is referred to as participatory geographic information systems (PGIS). PGIS is a process through which community members - that is people at grassroots level - become involved in spatial planning. PGIS has been touted as the 'democratization of GIS' (Dunn, 2007: 616). The printed versions of the questionnaires were accompanied by maps and coloured sticker dots with which respondents could indicate locational preferences, while the online version provided a map with a grid. The data analyses were performed with SPSS (frequencies and cross-tabulations) and ArcGIS (digitizing of PGIS data and creation of maps).

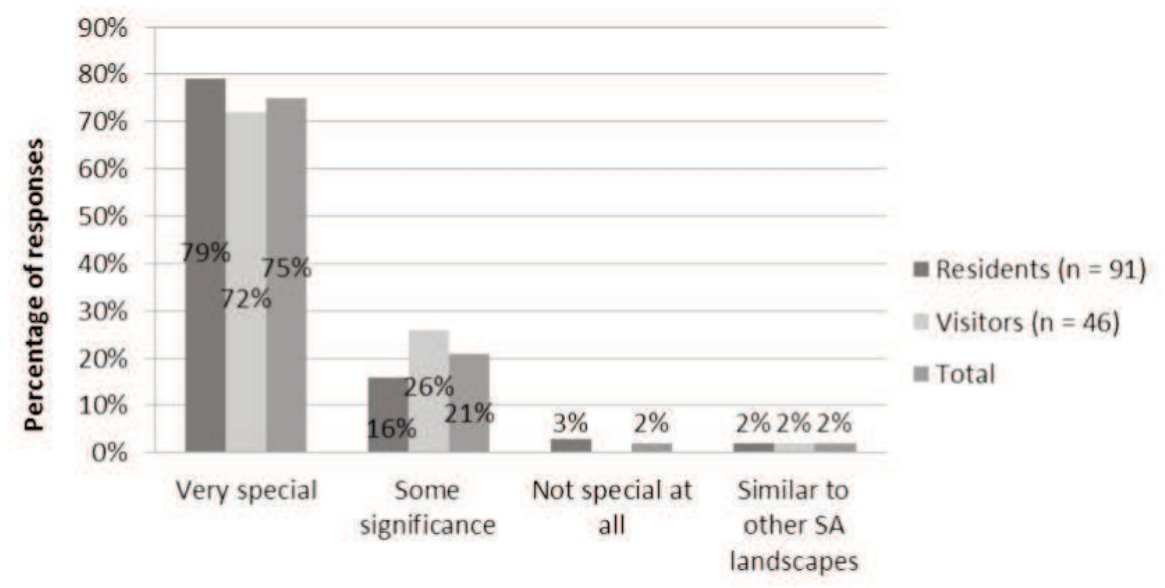

Qualitative rating physical landscape

Figure 3: Nature of the physical landscape of the West Coast region Source: Lombard, 2012 


\section{Results and discussion}

The WCR is known for its simple, undeveloped and mostly natural landscapes. Potential disturbances of these fine and prized landscapes by wind farm developments may undoubtedly generate grave concern from various stakeholders in the WCR. Respondents were asked to indicate how special they consider the physical landscape of the WCR to be. Figure 3 displays their responses. The majority of residents and visitors regard the region's physical landscape as very special and they supported this by naming the fynbos vegetation, undisturbed coastlines, diversity and richness of floral species and the wide open and beautiful character of the landscape as features that make the landscape distinctive. Considering, among other factors, the special nature of the physical landscape, respondents were questioned on their support for or objection to proposed wind farm projects in the WCR.

The results indicated that $70 \%$ of both residents of and visitors to the WCR showed strong support for the development of wind farms in the region in accord with most international pre-impact surveys done on the social support of wind farm projects where only a minority is against the development of these projects. This section first explores respondents' reaction the visual impact of wind farms in the WCR, after which the focus shifts to land use diversification and landscape values associated with wind farms.

\subsection{Visual impact of wind farms in the WCR}

The natural landscapes of the WCR will experience scenic interference to a greater extent than in areas with developed landscapes. Respondents were presented with lists of both the advantages and disadvantages of wind energy as extracted from international literature which they had to rate on a Likert scale in accordance to how important they found the advantages to be and the degree of disturbance generated by the disadvantages. The disadvantages where weighed as not disturbing at all (-2), somewhat disturbing (-1), neutral (1), disturbing (2) and very disturbing (3). The total of each category was divided by the total respondents multiplied by 3 ( $n$ x 3) (as if all respondents indicated the disadvantage to be very disturbing) and expressed as an index value with 100 as the highest value. The advantages were weighed as unimportant $(-2)$, low importance (-1), neutral (1), important (2) and very important (3). The total of each category was then divided by the total number of respondents multiplied by 3 ( $\mathrm{n} \times 3$ ) (as if all respondents indicated the advantage to be very important) and expressed as an index value with 100 as the highest value. The results are given in Tables 2 and 3 .

The drawback of wind turbines being perceived as ugly and so detracting from the scenic value of natural landscapes was appraised as the least disturbing liability which indicates that respondents have low levels of unease about the visual intrusion

Table 2: Respondents' weighted ratings of the disadvantages of wind energy (100 = very disturbing)

\begin{tabular}{lccc}
\hline Disadvantages & Residents $(n=98)$ & Visitors $(n=47)$ & Total \\
\hline Wind energy can be more expensive than other sources & 36 & 22 & 31 \\
\hline Turbine blades can harm flying wildlife & 25 & 20 & 28 \\
\hline Wind turbines may impair radio and television signals & 28 & 17 & 24 \\
\hline Wind turbines might deter tourists from visiting certain areas & 28 & 15 & 23 \\
\hline Wind energy potential varies seasonally and daily & 22 & 22 & 24 \\
\hline Wind turbines may be noisy & 25 & 3 & 16 \\
\hline Wind turbines are perceived as ugly and so detract from the & 9 & 12 & 2 \\
scenic value of natural landscapes & & & \\
\hline
\end{tabular}

Table 3: Respondents' weighted ratings of the advantages of wind energy (100 = very important)

\begin{tabular}{lccc}
\hline Advantage of wind energy & Residents $(\mathrm{n}=98)$ & Visitors $(\mathrm{n}=47)$ & Total \\
\hline Produces no atmospheric emissions & 90 & 91 & 91 \\
\hline No air pollution & 89 & 91 & 90 \\
\hline Increases electricity supply & 86 & 87 & 86 \\
\hline Resource (wind) used to generate electricity is free & 78 & 76 & 77 \\
\hline Land parcels used for wind turbine installations can still be used & 68 & 74 & 70 \\
for farming & 65 & 66 & 65 \\
\hline Conserves fossil fuels for future generations & 52 & 64 & 56 \\
\hline Wind turbines are symbols of commitment to renewable energy & 46 & 72 & 55 \\
\hline Produces economic gain for communities & 45 & 72 & 54 \\
\hline Creates new employment opportunities & 5 & 24 & 5 \\
\hline Increases tourism activities (as attractions) & & & 5
\end{tabular}


of wind farms in the WCR. This result is unexpectedly positive as Wolsink (2007) and Pasqualetti (2011) both assert that the visual intrusion of wind farms is the most controversial issue surrounding their development.

Another way of exploring the attitude of respondents to the adverse scenic impacts of wind farms was to show them a collage of photographs. After being instructed to observe the photographs, they were asked if they wanted to change their earlier answers to the questions whether they would support the development of wind farms in the WCR. All the residents and visitors declared that they would not change their answers. The reasons provided were that wind turbines are aesthetically more pleasing than nuclear reactors; they do not have any deterring effect; and they look good in other countries. This indicates the very subjective nature of the scenic perception of wind turbines.

\subsection{Wind farms and land use diversification in the WCR}

Wind farms afford famers an economic opportunity to earn income through supplying land to developers. Table 3 shows that the advantage of using land parcels for farming after installation of wind turbines is considered cardinal for both visitors to and residents of the WCR.

Wind farm development can secure agricultural sustainability over the long run with economic security derived from renting portions of land to wind farm developers. According to Loubser (2011) of the Vredenburg Agricultural Society, wind farm development is a way to sustain the already struggling agricultural sector of the WCR.

A possible reason for the anomaly on the scenic impact of wind farms also present itself in Table 3. Since 2008, South Africa has experienced a severe electricity crisis (Inglesi, 2010; Clohessy, et al., 2014) periodically suffering countrywide blackouts. The reserve margin - the excess of generation capacity over peak demand - is also contributing to the power crisis where this reserve has shrunk to about $8 \%$ against the international standard of at least 15\% (Cary, 2012; The Economist, 2008). It is therefore not surprising that a rating of 86 was given to the possible increase in electricity supply.

Using scale-based approaches such as the above is sufficient, but can be strengthened by incorporating map-based approaches such as PGIS. The

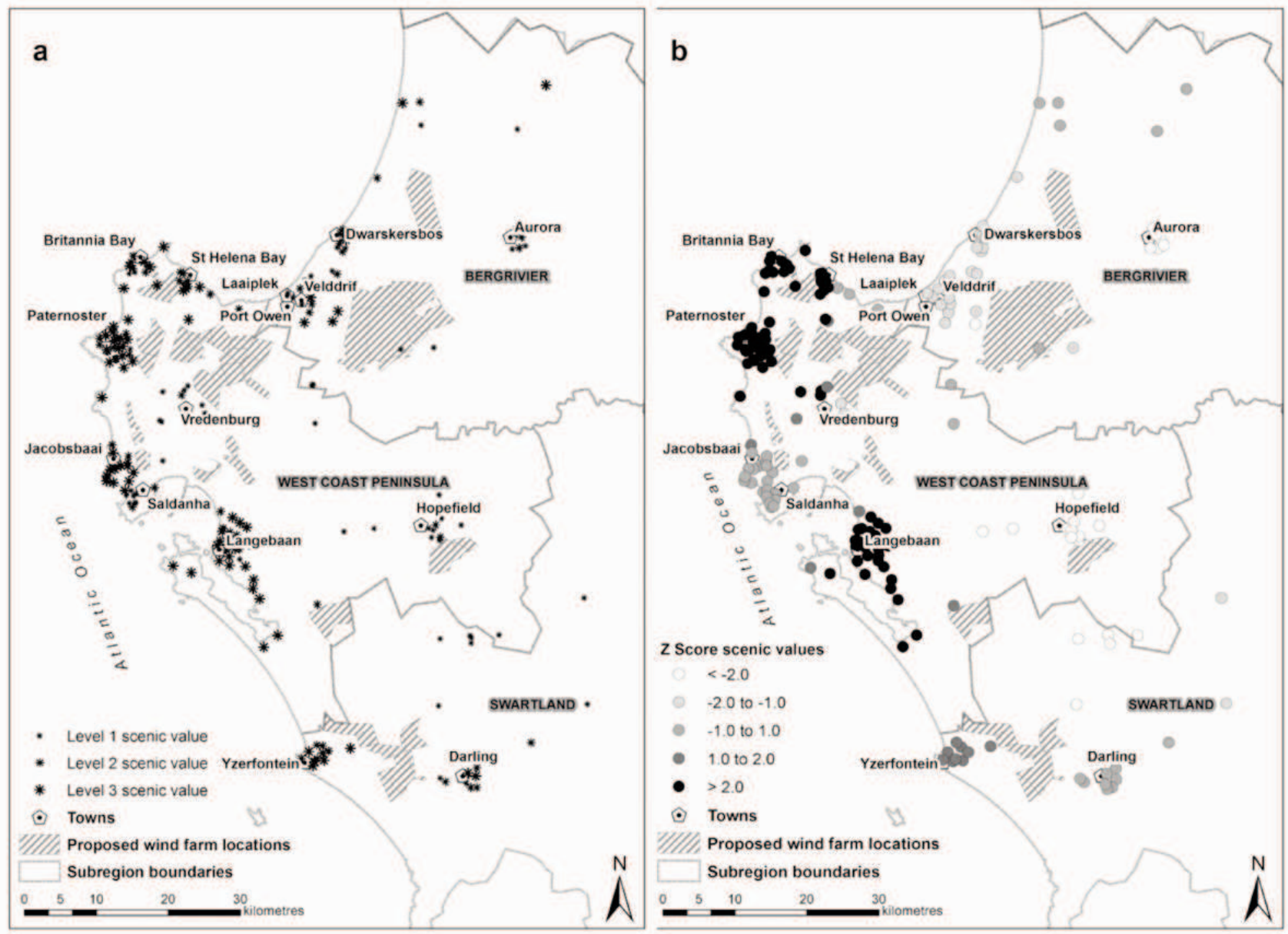

Figure 4: Scenic value of landscapes in the West Coast region: (a) Distribution of dots placed by respondents; (b) Hot Spot analysis results

Source: Lombard, 2012 
PGIS exercise in this study was specifically focused on landscape values from a participatory planning perspective.

\subsection{Wind farms and landscape values of the WCR}

The PGIS exercise in the questionnaire required respondents to indicate on a map the landscape value of places they deem to possess scenic/aesthetic and economic value.

This is a descriptive mapping process of landscape valuation. The respondents had to rank the scenic and economic value of their chosen places on a scale of one to three with three being the most prominent (exceptional). The distribution of these values was analysed by evaluating the spatial clustering of values as a dimension of spatial analysis. According to Longley et al., (2005: 316) 'spatial analysis can reveal things that might otherwise be invisible - it can make what is implicit explicit.' In this instance, spatial analysis is used to locate the areas where the highest concentrations of the two landscape values are found. To discern these patterns, a specific tool of spatial analysis was employed, namely Hot Spot analysis which 'identi- fies statistically significant spatial clusters of high values (hot spots) and low values (cold spots)' (ArcGIS Desktop, 2011). Figure 4a shows the distribution of places where the resident and visitor respondents consider the landscape to have scenic value. To make sense of this distribution, the results of the Hot Spot analysis are shown in Figure 4b.

Respondents indicated a total of 194 places with scenic value with $31 \%$ classified as level 1, 32\% classified as level 2 and $37 \%$ classified as level 3 . From the general distribution, it is evident that scenic value is predominantly associated with coastal areas. It is a cause for disquiet that some places of scenic value coincide with the proposed wind farm developments, for example, at St Helena Bay and Paternoster. Wind farm development in these two areas of clustered scenic value will have to be handled judiciously by wind farm developers. The second landscape attribute respondents were asked to map according from little to exceptional value which is the economic value of the WCR landscape. The chosen locations are portrayed in Figure $5 \mathrm{a}$ and the economic hot spots in Figure 5b.

The respondents identified 178 places with economic value with $26 \%$ classified as level $1,34 \%$ as

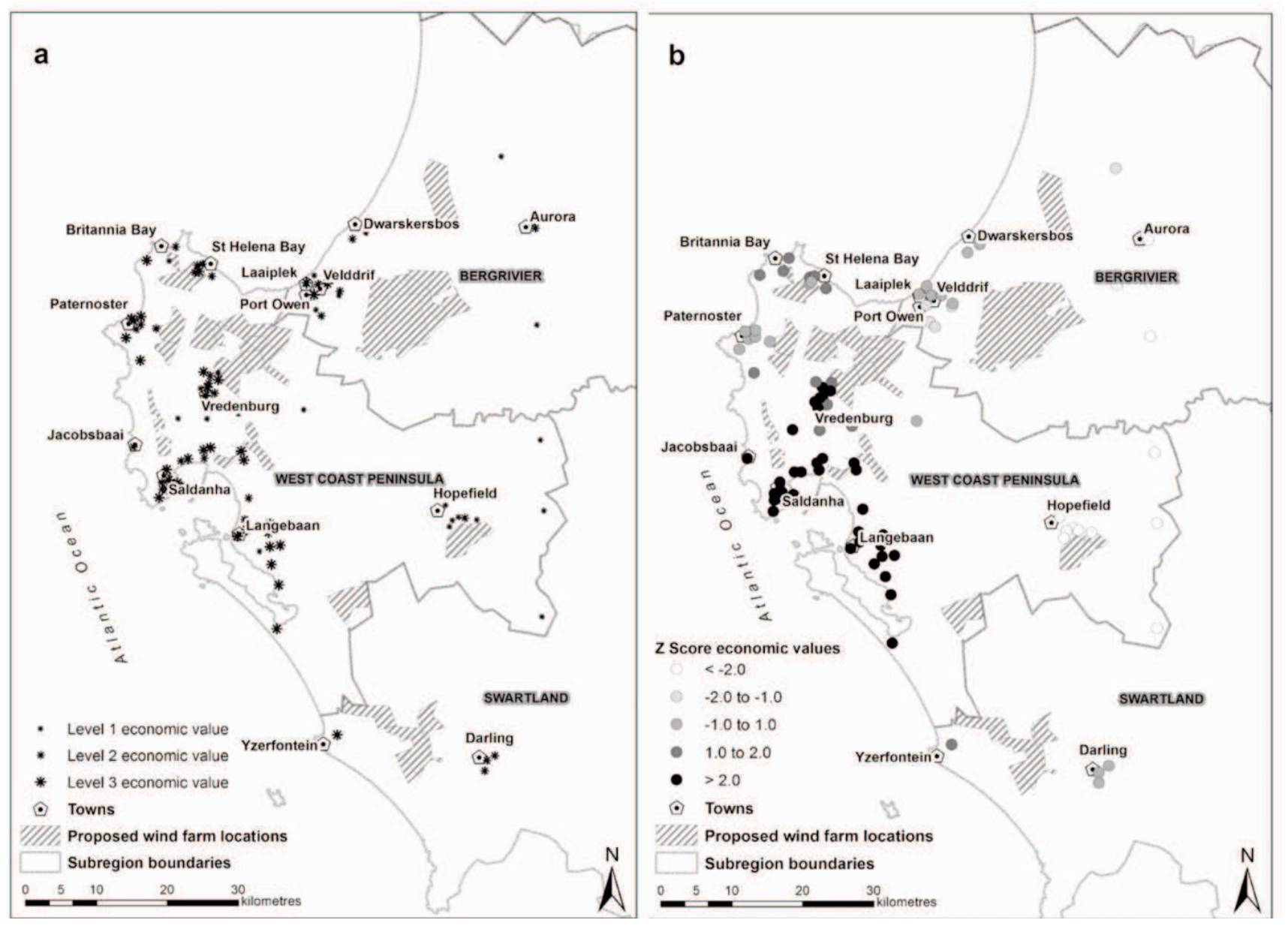

Figure 5: Economic value of landscapes in the West Coast region: (a) Distribution of dots placed by respondents; (b) Hot Spot analysis results

Source: Lombard, 2012 
level 2 and $40 \%$ as level 3 . The areas identified with the most prominent economic value occur in the West Coast Peninsula sub-region (78\%) and are found in the Vredenburg, Saldanha and Langebaan areas according to the hot spot analysis. Vredenburg is the business centre of the WCR so that this economic hot spot is not surprising. The harbour industry and steel mill in the Saldanha area assign a high level of economic value to this area and Langebaan is a tourism hub of the WCR with various tourism-associated activities distinguishing the economy. Notable in Figure $5 \mathrm{~b}$ is that the inland areas where mainly agriculture is practised are cold spots regarding economic value because agriculture exhibits a relatively low performance in comparison to the industries in the Langebaan, Saldanha and Vredenburg areas. The addition of wind farms to these agricultural areas may increase the associated economic value.

The research has shown that very few of the respondents are opposed to wind farm developments, provided that the development occurs in the appropriate places. Therefore, as a finale to the PGIS exercise, respondents were invited to indicate on a map where they believe appropriate locations for wind farms are (Figure 6a) as well as to map where wind farms should not be located (Figure $6 b)$.

The distribution of places where the wind farms should be located clearly tends toward the interior of the region away from urban settlements. The inland locations are unfortunately not always endowed with exceptional prevailing wind resources like those closer to the coast (Diab, 1995). Some respondents indicated that wind farms should be located offshore, but no offshore wind farms have yet been proposed for South Africa. Figure 6a does, however, show that a number of these appropriate places coincide with the areas where wind farms have already been proposed. There are fewer points in the Paternoster, St Helena Bay and Britannia Bay areas compared to Figure $6 \mathrm{~b}$ which indicates that the wind farms close to these two locations are the definite ones that deserve more attention from the developers. Locations close to the coast emerge as no-go areas with an emphasis on the areas surrounding St Helena Bay, Britannia Bay and Paternoster.

The community of Paternoster has formed a group 'NoWindfarmsPaternoster' to express their
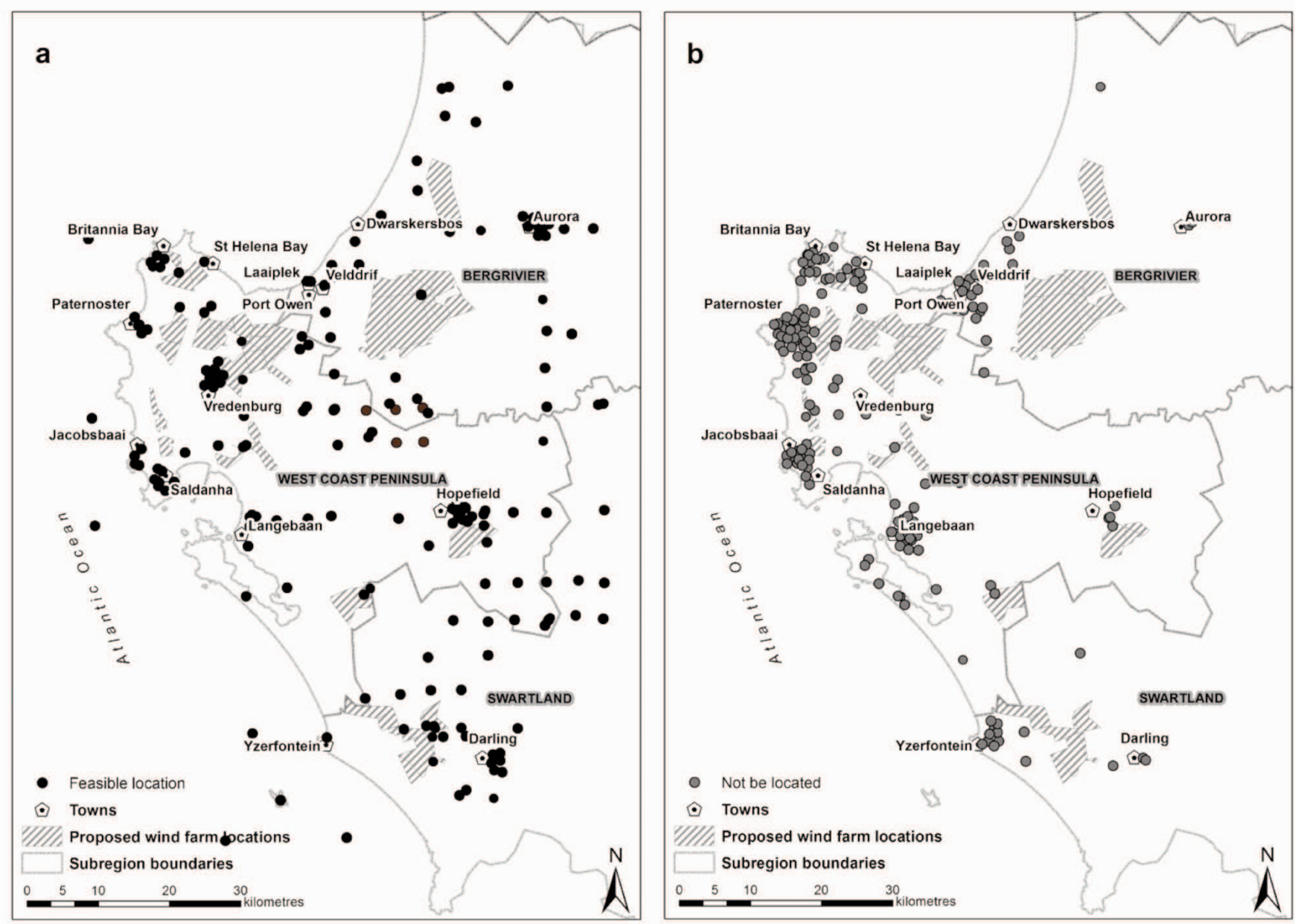

Figure 6: Respondents' view on the location of wind farms: (a) Where wind farms should be located; (b) Where wind farms should not be located

Source: Author 2012 
discontent with the chosen locality of the proposed wind farm project in their immediate vicinity. During the group's meeting on 19 December 2011 their consternation became patently clear that the marginalized community of Paternoster had not been informed nor involved during the environmental impact assessment (EIA) process of the particular project. Only the literate members of the community have the opportunity to actively involve themselves in the proposed projects because the newspaper advertisements and information documents in the library are largely inaccessible to less literate citizens. The action group expressed the need for the developers and consultants to verbally and personally inform the marginalized groups about the meetings. PGIS also presents an opportunity for illiterates to take place in spatial planning processes. In St Helena Bay and Britannia Bay, residents believe that the wind farm project will benefit the community as a whole, although they do raise concerns, but to a lesser degree than the case with the Paternoster wind farm which has already been approved for construction. Heather-Clark (2011), of Environmental Resources Management (ERM), reiterated it during a meeting of the West Coast Business Chamber that there is no 'yes' or 'no' answer to whether wind energy is the solution for the WCR, but emphasized that exploration of the issues associated with the proposed developments must be done to establish the most appropriate locations from both developer and community perspectives. The positives of any location must exceed the negatives.

\section{Conclusion}

From the international literature it became evident that wind farm developments can influence the physical landscape mainly in two ways, namely impacting on the aesthetics of the landscape as well as diversifying the land use practiced. The visual intrusion is considered the most concerning impact of wind farm projects. However, the respondents of this study do not find the visual impact to be significantly concerning.

Seventy per cent of all respondents support the development of wind farms in the WCR in spite of regarding the landscape as very special. It became imperative throughout the study that a visual impact assessment is simply not enough to establish the impact of wind farms on natural landscapes, especially considering that the visual impact does not play a role in this region. Investigation of the sensitivity, value and character of the landscape can be enhanced using a participatory planning approach such as PGIS. This study mainly focused on landscape values to indicate the valuable contribution of a grassroots mapping exercise.

\section{References}

ArcGIS Desktop. (2011). ArcGIS Desktop 10. ArcGIS Inc. Online Help. Online.

http://help.arcgis.com/en/arcgisdesktop/10.0/help/ind ex.html\#//005p00000010000000. (Accessed 10 June 2012).

Brown, G. and Raymond, C. (2007). The relationship between place attachment and landscape values: Toward mapping place attachment. Applied Geography. 27: 89-111.

Brusa, A. and Lanfranconi, C. (2006). Guidelines for realization of wind plants and their integration in the territory. Paper delivered at the EWEC 2006, Milano.

Cary, M. (2012). Energy efficiency and renewable energy resources. Energize. April, 3.

Clohessy, C.M., Brettenny, W., Sharp, G. and Vorster, F. (2014) Evaluation of noise levels of two micro-wind turbines using a randomised experiment. Journal of Energy Southern Africa. 25(1): 19-25.

Diab, R.D. (1995). Wind atlas of South Africa. Pretoria: Department of Mineral and Energy Affairs.

Dunn, C.E. (2007). Participatory GIS - a people's GIS? Progress in Human Geography. 31: 616-637.

European Wind Energy Association (EWEA). (2010). Wind energy: The facts. 2nd ed. London: Earthscan.

Heather-Clark, S. (2011). Wind energy: The good, the bad and the ugly. Paper delivered at meeting of the West Coast Business Chamber on 28 July, Saldanha.

Hecklau, J. (2005). Visual characteristics of wind turbines. Proceedings of the NWCC Technical Considerations in siting wind developments. Online. http://www.nationalwind.org/assets/siting/proceedings.pdf. (Accessed 2 September 2012).

Henningsson, M., Jönsson, S., Ryberg, J.B., Bluhm, G., Bolin, K., Bodén, B., Ek, K., Hammarlund, K., Hannukka, I., Johansson, C., Mels, S., Mels, T., Nilsson, M., Skärbäck, E., Söderholm, P., Waldo, A., Widerström, I. and Åkerman, N. (2013). The effects of wind power on human interests: A synthesis. Swedish Environmental Protection Agency, Report 6545. January 2013. Online. http://www.naturvardsverket.se/Documents/publikationer6400/97891-620-6545-4.pdf. (Accessed 5 June 2013).

Inglesi, R. (2010). Aggregate electricity demand in South Africa: Conditional forecasts to 2030. Applied Energy. 87: 197-204.

Katsaprakakis, D.A. (2012). A review of the environmental and human impacts from wind parks: A case study for the Prefecture of Lasithi, Crete. Renewable and Sustainable Energy Reviews. 16: 2850-2863.

Lobley, M. and Winter, M. (2009). Introduction: Knowing the land. In Winter, M. and Lobley, M. (eds). What is land for? The food, fuel and climate change debate. 1-20. London: Earthscan.

Lombard, A. (2010). Feasibility of wind farms in the Western Cape. Honours research report.

Stellenbosch: Stellenbosch University, Department of Geography and Environmental Studies.

Lombard, A. (2013). Wind energy landscapes, place attachment and tourism in the Route 27/West Coast region of South Africa. Master's thesis. Stellenbosch University, Department of Geography and 
Environmental Studies, Stellenbosch.

Longley, P.A., Goodchild, M.F., Maguire, D.J. and Rhind, D.W. (2005). Geographic information systems and science. 2nd ed. Chicester: John Wiley \& Sons, Ltd.

Lothian, A. (2008). Scenic perceptions of the Visual Effects of Wind Farms on South Australian Landscapes. Geographical Research. 46(2): 196207.

Loubser, K. (2011). Boere versprei risiko met windplase. Weslander. 8 September: 17.

Manwell, J.F., McGowan, J.G. and Rogers, A.L. (2002). Wind energy: Theory, design and application. Chichester: Wiley.

Pasqualetti, M.J. (2000). Morality, space, and the power of wind energy landscapes. Geographical Review. 90: 381-394.

Pasqualetti, M.J. (2001). Living with wind power in a hostile landscape. In Pasqualetti, M.J., Gipe, P. and Righter, R.W. (eds). Wind power in view: Energy landscapes in a crowded world. 153-172. San Diego: Academic Press.

Pasqualetti, M.J. (2011). Social barriers to renewable energy landscapes. The Geographical Review. 101: 201-223.

Stanton, C. (2005). Visual impacts: UK and European perspectives. Proceedings of the NWCC Technical Considerations in siting wind developments. Online. http://www.nationalwind.org/assets/siting/proceedings.pdf. (Accessed 2 September 2012).

The Economist. (2008). The dark ages: South Africa's power crisis is having wider repercussions. Online. http://www.economist.com/node/10609230. (Accessed 30 May 2013).

Valentine G. (1997). 'Tell me about...': Using interviews as a research methodology. In Flowerdew $\mathrm{R} \&$ Martin D (eds) Methods in human geography: A guide for students doing a research project, 110-126. Edinburgh Gate: Addison Wesley Longman.

Van de Wardt, J.W. and Staats, H. (1988). Landschappen met windturbines. Leiden: University of Leiden.

West Coast District Municipality. (2012). Integrated Development Plan 2012-2016 Online. http://westcoastdm.co.za/wp-content/uploads/2012/06/WCDMIDP-2012-16-Final-Approved1.pdf. (Accessed 20 July 2012).

Wolsink, M. (2007). Planning of renewables schemes: Deliberative and fair decision-making on landscape issues instead of reproachful accusations of noncooperation. Energy Policy. 35: 2692-2704.

Wolsink, M. (2012). Wind power: Basic challenge concerning social acceptance. In: Meyers, R.A., (Ed) Encyclopaedia of Sustainability Science and Technology, SpringerReference. 17: 12218-12254. 